\title{
DE PERSONAE HUMANAE FUNDAMENTALIBUS IURIBUS TUENDIS, QUID SCHEMATA FUTURI CODICIS IURIS CANONICI CAVEANT
}

Etsi huius praelectionis materia ad ius condendum respicit, accedit, quod de unoquoque argumento multa essent dicenda de iure vigenti, immo vero et de canonici iuris historia, si vellemus recte inspicere et perspicere, quid in futuro iure canonico opportunius sit cavere, et ea, quae proposita sunt, schemata novi Codidis accurate considerare et aestimare.

\section{DE LEGE ECCLESIAE FUNDAMENTALI}

Qui ad studium de humanae personae fundamentalibus iuribus tuendis in futuro Ecclesiae iure operam dare vult, ante omnia animum convertit ad schema illud Legis Ecclesiae Fundamentalis, quod novum omnino in canonicae legislationis historia visum est, ita ut de eo multa iam prolata sint publica et privatim iudicia diversissima et probantia quidem et reprobantia. Quod autem ad nostram rem attinet, animadvertendum est non defuisse qui aut omnino non intelligentes, aut certe exaggerantes iuris canonici munus circa iura hominum tuenda, propugnaverint, ut in eo schemate ea tantum continerentur, quae ad fundamentalia iura, vel saltem ad haec iura in Eccesia, tuenda pertinerent; alios autem fuisse, qui hunc vitantes excessum, recenseri tamen in eo schemate fundamentalia hominum iura omnia, et fundamentalia christifidelium iura velint.

Quidquid est ceterum de huiusmodi opinionibus, certum est in eo schemate multa quidem inesse de christifidelium iuribus, nonnulla quoque e quibus principia de hominum iuribus fundamentalibus desumi possint, ita tamen servato competentiae ordine, ut Ecclesia non invadat in ordinem, qui ad status potestatem pertinet; verum schema illud, sicut 
cetera schemata ad novum ius canonicum parandum redacta, non tendunt nisi ad Ecclesiae vitam et actionem moderandam, ideoque non eorum est principia generalia iuris divini vel naturalis, de quibus innumera sunt ecclesiastici magisterii documenta, omnia enuntiare, nisi quatenus id necessarium vel utile sit ad normas canonicas intelligendas.

Cum autem permulta de eo schemate et a theologicarum et a iuridicarum scientiarum cultoribus scripta sint, nec solum generatim, sed etiam proprie de iis respectibus, qui maxime ad funlamentalia hominum iura attinent, liceat mihi hic ad ea scripta remittere, deque duobus aliis schematibus potius sermonem habere. Rursus autem de eo schemate mentionem mox faciam, ubi quidpiam de principio quodam iuris poenalis delibabo.

\section{DE PROCEDURA ADMINISTRATIVA}

Praeter autem schema de fundamentali Ecclesiae lege, maxime connectitur cum materia de hominum iuribus tuendis schema illud de procedura administrativa. Ideo enim et primum esse conceptum videtur et proprie redactum, ut necessitatem actionis administrativae seu gubernativae in Ecclesia cum personarum iuribus tuendis ac servandis componeret. Nam ita debent in Ecclesia fundamentalia hominum iura exerceri et protegi, ut superius bonum, quod per administrativam Ecclesiae activitatem, immo vero per totam regiminis activitatem, fovetur, non impediatur; ideoque fieri etiam potest, ut ea iura limitari debeant, et ipsos actus heroicos Ecclesia possit praecipere quibusdam saltem personis, si supernaturalis finis id exigat. Ex quo patet, quam necessariae sint normae iuridicae, quae rationem procedendi in gubernanda Ecclesia moderentur, et quam arcte eiusmodi normae cum hominum iuribus protegendis connectantur.

Verum quidem est in administrativa Ecclesiae activitate hoc supremum debere esse duplex principium: (a) omnes administrativos actus, seu decreta, semper sint omnino iustitiae conformes, et simul tales, quae maxime respondeant Ecclesiae fini, id est animarum bono: (b) si quod forte decretum alicui iniustum damnum inferat, is patienter toleret eiusmodi damnum suae utilitatis sacrificium veluti in poenitentiam acceptans, nisi hoc sacrificium animarum saluti noceat. Verum tamen est quoque legem non posse hoc sacrificium singulis hominibus generatim imponere, quod esset nimis hominum iura comprimere sine superiore neccessitate; debet igitur lex remedia statuere ad administrativos actus emendandos, si forte minus consentanei sint animarum bono, vel si cui iniustum inferant damnum. Necessitas autem huiusmodi remedia statuendi, quae in Codice instant, sed satis esse non videntur, adeo nostra 
praesertim aetate persentitur, ut ii quoque normas perfectiores de hac re dandas propugnent, qui sive quod ignorant, quid sit Ecclesia sive quod ignorant quid sit ius canonicum, ius ab Ecclesia aboleri et exterminari volunt, quasi cum germana Ecclesiae indole componi non possit.

Schema autem canonum, quod, ,de procedura administrativa” inscribitur, eiusmodi remedia ex accurato studio proponere conatur, multiplicibus profecto necessitatibus et periculis - quae in hac re saepe difficilius vel tardius perspiciuntur, nisi postquam usus docuerit - obviam ire, quantum mens humana potest prospicere, curans.

Itaque hoc schema imprimis aliquas dat normas, aliasque Episcopalibus Conferentiis ferendas permittit, de cautionibus servandis in decretis administrativis proferendis, quae normae simul et efficacius personae iuribus tuendis et meliori gubernandi rationi cavent.

Norma enim proponitur, ut superior, antequam decretum ferat, necessarias notitias et probationes exquirat eosque omnes saltem audiat, nisi impossibile vel omnino superfluum sit, quorum iura ex decreto laedi possint; ut petitori vel recurrenti, etiam legitime contradicenti, si velint, notitias et probationes patefaciat, quae sine publici vel privati damni periculo cognosci possint, atque rationes forte contrarias ostendat, data eis facultate respondendi etiamque, si utile id censeat, patronum vel peritum constituendi. Plures autem cautiones praevidentur, si agatur de ferendo decreto, quo recursus adversus aliud decretum decidatur.

Alia norma cavet áe casu, quo superior, qui decretum ferre debeat, id facere negligat.

Alia norma iubet, ut in decretis ferendis id prae oculis habeatur et intendatur, quod animarum saluti et publico bono maxime conducere videatur, servata quidem lege et generali et particulari, iustitia, canonica aequitate, et ut decretum scripto feratur, expressis, saltem summarie, motivis.

Etsi autem hae normae nimis generales possunt videri, at difficile sane est magis minutas normas generatim de quibuslibet decretis redigere; de singulis autem decretorum generibus normae speciales, etiam a Conferentiis Episcopalibus, dari poterunt. Ne autem arbitria in administrativis decretis ferendis compescens, arbitria in decretis corrigendis foveat, prudentissime operari debet legislator. Ut autem ita se gerat, fieri potest, ut nonnumquam non possit defectuum omnium correctio contra auctoris voluntatem imponi, sed eorum tantum, quos ipse legislator singillatim recensere possit. Nam accidere potest, ut si omnium defectuum correctio sine discrimine imponeretur, iam nulla haberetur certitudo - neque enim omnium iudicia et aestimationes semper sunt concordes - et administrativa Ecclesiae activitas veluti in vinculis esset cum gravissimo animarum damno. 
Praeterea fit, ut in quibusdam casibus ea tantum decretorum vitia possint invocari ad decretum corrigendum vel evertendum, quae sint propria legis violatio, minime autem quae tantummodo esse dicantur erronea boni animarum aestimatio ac erroneum iudicium de pastoralibus necessitatibus. Quod schema generalibus normis proponit, si recursus adversus decretum ad tribunal administrativum mittatur; cetera autem vitia, quae ,de merito" solent dici, possunt secundum schema tunc tantum invocari, si recurratur non ad tribunal administrativum, sed ad superiorem hierarchicum. Ceterum haec norma magis consona est Ecclesiae constitutioni, ne videlicet tribunalia administrativa - quae schema instituenda proponit in tota Ecclesia - comprimant Episcoporum nativum ius gubernandi eam populi Dei partem, quae unicuique commissa est. Ita haec norma tandem etiam ad iura hominum tuendam tendit, cum eiusmodi iura non debeant tantum considerari in subditis erga superiores, sed etiam in superioribus erga subditos.

Insunt autem in schemate de administrativa procedura normae quaedam, ex Americanarum quarundam dioecesium usu desumptae, quae, vetera quidem principia (cfr. CIC can. 1925) ad rem novam extendentes, et superiorum et subditorum tranquilitati cavent, recursus inutiles vel fundamento carentes fortasse imminuent, fastidia et dedecora ex recursibus, quatenus fieri possit, avertere nituntur et supremum, quod supra dixi, principium in hac re veluti commendare videntur.

„Valde optandum est - dicit enim schema - ut quoties quis gravatum se decreto putet, non fiat inter ipsum et decreti auctorem contentio, sed inter eos de aequa solutione quaerenda communi consilio curetur, gravibus quoque hominibus ad mediationem et studium forte adhibitis ita, ut vel per voluntariam decreti emendationem vel per iustam compensationem vel per aliam idoneam viam controversia vitetur vel dirimatur".

Ad huiusmodi autem solutiones maxime fovendas schema proponit, ut nullus recursus fieri possit, nisi quis antea petierit ab ipso decreti auctore decreti revocationem vel emendationem; praeterea, ut conferentia Episcopalis possit statuere, ,ut in unaquaque diocesi officium quoddam vel consilium stabiliter constituatur, cui secundum normas ab ipsa Conferentia statuendas munus sit aequas solutiones quaerere et suggerere, praesertim si agatur de decretis ab Episcopo vel ab auctoritate ei subiecta latis”; ut ,etiam ... si Conferentia id non iusserit, possit Episcopus eiusmodi consilium vel officium constituere"; et ut, si recursus fiat, iudex vel superior, qui de recursu videt, recurrentem et decreti auctorem debeat, quandocumque spem boni exitus perspiciat, ad eiusmodi solutiones quaerendas hortari. 


\section{DE SANCTIONUM SEU POENARUM DISCIPLINA IN ECCLESIA LATINA}

Transeo nunc ad aliud schema, quo canones proponuntur - pauci sane, sunt enim septuaginta tres - de iure poenali, ad quintum Codicis vigentis librum subrogandum.

Antequam autem de huius schematis canonibus, quod attinet ad mihi propositam materiam, dicam, animadverto in schemate de Lege Ecclesiae Fundamentali, de quo ante locutus sum, tangi quoddam principium, quod ad hominum iura in re poenali tuenda pertinet: principium, dico, de nulla poena irroganda, nisi in casibus ipsa lege definitis ac modo a lege ipsa determinato. Verum fortasse nimis dixi hoc principium in eo schemate tangi. Nam fuerunt quidem, qui propugnaverint, ut principium illud ibi enuntiaretur, neque tamen omnes canonistae in hoc consentiunt, neque igitur potest praevideri, quid eveniat in Legis Fundamentalis ultimo textu. Si autem attendamus ad poenalis iuris munus in Ecclesia, quod ad animarum salutem, sicut ceterae iuris canonici partes, tendit et tendere debet, facile dubitabitur utrum illud principium debeat in Ecclesia quoque valere. Quanto rectius Codex Iuris Canonici omisit illud principium enuntiare, in delicti definitione necessitatem praeviae legis vel praevii praecepti asserens (can. 2195), sed normam statuens (can. $2222 \S 1$ ), quae, ei principio minime derogans, necessitatibus nullo modo praevisis satis accurate cavet. Quod similiter effecit etiam novum schema de iure poenali in can. 73.

Complura quidem in schemate documenti ,quo disciplina sanctionum seu poenarum in Ecclesia Latina denuo ordinatur" insunt, quae ideo proposita sunt, ut hominum iura in Ecclesia maiorem habeant tuitionem, eamque nostrae aetatis necessitatibus et optatis aptiorem. Huc sane pertinet illa ipsa proposita mutatio, cui multi iam canonistae et theologi scribendo adversati sunt. Mutationem, dico, circa excommunicationis effectus, cum proponatur in schemate, ut excommunicatus (et etiam interdictus) non arceatur a sacramentali peccatorum absolutione, sed tantummodo a ceteris sacramentis (sed excipitur etiam infirmorum unctio). Neque enim proposita haec vigentis iuris emendatio eo tendit, ut sacramentali absolutione poenitens cum Deo quidem reconcilietur, minime autem cum Ecclesia; sed eo, ut is et cum Deo et cum Ecclesia per sacramentalem peccatorum absolutionem reconciliari possit et eiusmodi iure ac possibilitate non careat, etiamsi in poenam adhuc quibusdam sacramentis aliisque spiritualibus bonis privetur, sive, quod iustum est, eum his bonis privari, sive quod per accidens ipse nequeat probare sibi hanc privationem esse auferendam. Ita videlicet fit, ut gravissima omnium privationum, quae ab Ecclesia infligi possint, numquam infligatur (si quidem quod in schemate proponitur approbabitur), et maximi 
momenti bono numquam homo, quamvis delinquens, privetur ab Ecclesia. Privabitur autem, quod patet, si non est rite dispositus ad peccatorum absolutionem recipiendam, sed a se ipso tunc privabitur, non ab Ecclesia ${ }^{1 .}$

Potestas leges particulares poenales et poenalia praecepta ferendi in schemate non solum non minuitur, sed eius exercitium quodammodo summopere fovetur. Verum, dum principium subsidiarietatis, quantum res sinit, servatur, incommodis cavetur, quae ex eius principii observantia evenire possunt, videlicet si non recte potestas regiminis exerceatur in Populi Dei servitium. Ad quod propositum consequendum in schemate normae quaedam proponuntur, quibus principia nonnulla, summaria quidem, enuntiantur, in his rebus, ne potestates non rite adhibeantur, servanda. Itaque potestates leges poenales ferendi et poenalia praecepta imponendi ita in schemate determinantur ac definiuntur, ut periculum vitetur, ne arbitrarium earum potestatum exercitium personae humanae iura laedat.

De poenis per decretum irrogandis vel declarandis, qua de re Codex paucas quidem easque lacunis plenas normas habet (cf. can. $1933 \S 4$ et 2225), hoc schema, etsi uno tantum canone, cautiones quasdam proponit, quae hominis personam melius tuendam sibi proponunt. Cautiones autem ideo magis necessariae videntur, quod in poenis per decretum irrogandis vel declarandis ,iura defensionis", quae vocant, minorem protectionem, utique ad publicum bonum et necessitatem, habentur. Itaque schema poenarum applicationem per decretum (quod in Codice dicitur ,,per modum praecepti”) tunc admittit, si ,graves obstent causae, ne iudicialis processus fiat, et probationes de delicto evidentes sint neque actio criminalis sit exstincta". Vetat praeterea per decretum irrogari vel declarari poenas perpetuas easque poenas lege particulari vel praecepto constitutas, quas lex vel praeceptum vetet, per decretum applicare. Hae normae autem complentur normis, quae in schemate de procedura administrativa, ut dixi, exprimuntur, quaeque, cum de qualibet administrativa procedura servari debeant, vigebunt, si illud schema lex fiat, etiam de procedura ad poenas per decretum irrogandas vel declarandas.

Bonae delinquentis famae ita schema cavit, ut infamiae periculum vitare iubeat, nisi cum forte bonum aliquod superius aliter fieri postulet. Ita proponitur in schemate, ut obligatio servandae poenae ex toto vel ex parte suspendatur, „quandiu reus poenam servare nequit sine periculo gravis scandali vel infamiae", nisi tamen aliquis ex his casibus eveniat: (1) quod poena sit notoria in loco, in quo delinquens versatur;

\footnotetext{
1 De hac re scripsi perpauca in „Prawo Kanoniczne” 19 (1976) p. 6-7.
} 
(2) quod superior poenae observantiam legitime urgeat 2 ; (3) quod observantia sit necessaria ad scandalum vel damnum reparandum. Ad eundem finem proponitur in schemate norma, qua obligatio fit cavendi, ,ne reus ullam ex remissionis petitione aut ex ipsa remissione infamiam patiatur, nisi quatenus id necessarium sit ad scandalum vel damnum reparandum" ita, ut in remissione quoque poenarum curet Ecclesia, ne malum delinquenti infligatur maius, quam bonum animarum exigat.

Hae autem, quas vidimus, narmae schematis de iure poenali, aliaeque passim aliquid ad hominum iura tuenda insertae, complementum omnes inveniunt in quadam norma, quae videtur praecipua omnium ad intellegendum ,spiritum" iuris poenalis in schemate propositi: ea est norma, quae universum ius poenale in Ecclesia veluti reicit in remedia omnino subsidiaria, cum iubeat Ordinarium poenas irrogandas vel declarandas, tunc tantum curare debere, ,,cum perspexerit neque fraterna correctione, neque correptione, neque aliis pastoralis sollicitudinis viis satis posse scandalum reparari, iustitiam restitui, reum emendari, idque praevideat poenis efficacius passe obtineri". Haec autem norma non absorbet neque subrogat alias normas (quales sunt in Codice vigenti can. $2223 \S 3$ et 2288 , qui emendati in schemate quoque servantur), quae permittunt poenas omittere, etiamsi lex vel praeceptum comminetur poenam obligatoriam. Omnes autem hoc sibi proponunt, ut poena, quae est magnum personnae malum, tunc tantum adhibeatur, cum ad maius malum vitandum necessaria videatur.

2 Superior autem ex schemate potest poenae observantiam urgere, si poena sit irrogata vel declarata; item, si delictum, poena latae sententiae punitum, certum sit ex iudiciali delinquentis confessione vel sit notorium, et ipse poenae observantiam utilem exsistimet ad scandalum vel damnum reparandum. 